\title{
Co Relation of Socio Economic Status to Awareness and Acceptance of Patient's to Prosthodontic Treatment
}

\author{
R. S. Rakhi Menon
}

\begin{abstract}
Aim: The aim of the study is to co relate the socio-economic status of patients reporting to saveetha dental college and hospital and their need for dental prosthetic treatment. Objectives: To assess the differences among gender, educational level, occupation and income status to dental condition and awareness and acceptance of prosthodontic treatment. Methodology: 150 partially and or totally edentulous patients reported in a private dental college will be included in the study. A pretested interviewer administered questionnaire will be issued to the patients.
\end{abstract}

Keywords: prosthetic

\section{Introduction}

Tooth loss is psychologically upsetting experience, and is considered to be a serious event in the life of a person, requiring significant psychological readjustment (1). Patients may suffer real or perceived detrimental effects following the loss of one or more teeth which substantially reduce the quality of life affecting them emotionally, socially, physically and psychologically $(2,3)$. The nonacceptance of edentulousness and the individual's feelings about dentures, which have been the traditional way of replacing missing teeth, are important for the acceptance of new dentures (4). Traditionally, missing teeth are replaced by removable partial dentures, fixed partial dentures and complete dentures(5).

\section{Material and Method}

A descriptive cross sectional study was done patients attending saveetha dental college regarding their knowledge and awareness on replacement of missing teeth. The survey consisted of a self-administered questionnaire given to patients aged 20 years or older who had atleast one missing tooth. The questionnaire comprised of 11 questions. Questions were regarding educational status, socio economic status, missing teeth and replacement techniques, habits.

\section{Results}

A patient population of 150 participated in the study of which 65 were females and 85 were males which corresponds to $43.3 \%$ of the study population as females and $56.6 \%$ as males. The average age of the study group was 38.3 years with 23 years and 60 years of age being the youngest and oldest patients.

Patients having missing teeth

150 people had missing teeth of which 65 were females and 85 males. The examined population had missing teeth with $56.6 \%$ being males and $43.3 \%$ females. This survey found that males had higher occurrence rate of missing teeth. Most people had missing teeth for a time period a period of 1 year to 10 years.
Educational status of the patient:

30 out of 150 people who had missing teeth was illiterate accounting to $20 \%$. 44 among 150 people who had missing teeth had only primary education which accounts to $29.3 \%$.Out of 150 people with missing teeth, 46 people were literate without diploma or degree which is about $30.6 \%$.Only 30 out of 150 people accounting to $20 \%$ who had missing teeth was degree holders or professionals.

The socio economic status of the patient having missing teeth in regard to their annual income

The patients were classified into socio economic groups as low, upper middle class, lower middle class and high based on their annual income. 36 out of 150 population belong to low socio economic status that is $24 \%$. $46.6 \%$ of population fell into the category of lower middle class accounting to 70 out of 150 people having missing teeth. $22.6 \%$ of population belong to upper middle class accounting to 34 of 150 people with missing teeth. Only 10 out of 150 people who had missing teeth belonged to high class that is about $6.6 \%$. Therefore people with missing teeth were high in number among lower middle class.

\section{Private health insurance policy}

83 people out of 150 had received an health insurance policy which accounts to $55.3 \%$. The remaining have not acquired any health insurance policy.

Evaluation of number of missing teeth among patients: Out of 150 people having missing teeth, 64 of them have missing teeth less than 4 which accounts to $42.6 \%$. $24 \%$ among 36 people out of 150 have 5-10 missing teeth. Out of 150,22 people have 10-15 teeth missing which is about $14.6 \% .8$ out of 150 reported to hospital were completely edentulous that accounts to $5.3 \%$. The remaining 20 people had more than 15 teeth missing which is about $13.3 \%$

\section{Adverse habits}

Out of the 85 males, 68 males had some kind of adverse habits like smoking, tobacco chewing, pan chewing and/or alcohol. $80 \%$ of males with adverse habits had missing teeth. Out of 65 females with missing teeth, 4 females had the habit of pan or tobacco chewing which accounts to $4.7 \%$. 


\section{International Journal of Science and Research (IJSR) \\ ISSN (Online): 2319-7064}

Index Copernicus Value (2015): 78.96 | Impact Factor (2015): 6.391

Therefore relation between missing teeth among females and habits had less accountability.

\section{Reason for missing teeth:}

Out of 150 people having missing teeth, 77 of them gave dental caries has reason for missing teeth which accounts to $51.3 \%$. 63 people of them gave mobility has reason for missing teeth which is $42 \%$ among 150 people with missing teeth. 4 out of 150 people that is $2.6 \%$ with missing teeth gave trauma has a reason and the remaining were not aware of the cause of missing teeth.

\section{Patients who received prosthetic rehabilitation}

Out of 150 people having missing teeth, 95 of them haven't got a replacement done which counts for $63.3 \%$ Remaining 55 of the 150 people with missing teeth got their teeth replaced which counted for $36.6 \%$ of the population. Of the 95 people who haven't got replaced 43 were females and 52 males and of 55 people who got missing teeth replaced, 27 were female and 28 males.

\section{Patient's response to the question if they were willing to replace the missing teeth}

92 people out of 150 which is $61.3 \%$ of population who did not receive replacement before said that they were willing to get the missing teeth replaced now. Among this group 52 were males and 40 were females corresponding to $54.7 \%$ and $42.1 \%$ male and females respectively who were willing for replacement.

\section{Reasons for not seeking a prosthetic rehabilitation}

Out of 95 people with missing teeth not having replaced, $35.8 \%$ of this population didn't get replacement done because of lack of awareness or ignorance towards dental procedures which accounted for 34 people. Among the $32.6 \%$ that is 31 among the 95 had financial issues. $11.6 \%$ which is 11 of 95 had no sufficient facilities nearby for dental procedures. $20 \%$ which is 19 out of 95 had lack of accessibility to hospitals as they were from rural areas.

\section{Patient's preference on prosthetic treatment techniques}

38 out of 55 people who replaced missing teeth was aware of complete dentures and removable partial dentures but preferred fixed partial dentures.. Relatively less population preferred dental implants, about 8 out of 55. Out of 55, 8 reported were complete denture wearers and they preferred only removable prosthetic treatment.

\section{Discussion}

Since much of the tooth results from dental caries and periodontal disease, tooth loss is a reliable measure of a population's oral health status. The increase in the awareness of the oral health importance will lead to decline in the prevalence and extent of tooth loss. This study was undertaken to assess the prevalence and extent of denture use while also evaluating associated demographic factors such as gender, socio economic status and educational level.

Mattin and Smith, who worked on Asians living in England, 1995, examined dental cases of 1995 people and reported that $70 \%$ of the subjects used removable appliance.
Most studies have shown gender differences, with more males becoming edentulous than females. According to Marcus et al, there had no relationship of edentulism with gender.

\section{Conclusion}

Among the entire population in the survey $56.6 \%$ of male population and $43.3 \%$ of female population had missing teeth. Among them $63.3 \%$ of population didn't not get their lost teeth replaced where as $36.6 \%$ of them got their missing teeth replaced. Among the people with missing teeth, $30.6 \%$ of population was literate without degree or diploma followed by $29.3 \%$ of population who had received only primary education. Prevalence of missing teeth was high among population who belong to lower middle class accounting to $46.6 \% 42.2 \%$ of population had less than 4 missing teeth. $80 \%$ of males with adverse habits had missing teeth. Most of them gave dental caries (51.3\%) and periodontal disease (42\%) as reason for missing teeth. Males were willing to replace the missing teeth more compared to females.63.3\% of population have not replaced their missing teeth. $35.8 \%$ of the population didn't get replacement done because of lack of awareness or ignorance towards dental procedures, $32.6 \%$ had financial issues. When asked about their preference in prosthesis, most of them preferred fixed and very few wanted dental implants.

This study concludes that edentulism is based on a combination of various factors such as gender, education level, socio economic condition, awareness towards dental procedure.

\section{References}

[1] Ilgi Baran, Gulfem Ergun, Mustafa Semiz; SocioDemographic and economic factors affecting the acceptance of removable dentures; European journal of dentistry, 2007, Apr ; Vol 1, 104-110

[2] Marcus PA, Joshi A, Judith AJ, Morgano SM. Complete edentulism and denture use for elders in New England. J Prosthet Dent 1996;76:260-266.

[3] Mattin D Smith JM. The oral health status, dental needs and factors affecting utilization of dental services in Asians aged 55 years and over resident in Sothampton.Br Dent J 1991;170:369-372

[4] Olaide Shakeerah Gbadebo, Folake Barakat Lawal, 1 Amidu Omotayo Sulaiman, and Deborah Mojirade Ajayi; Dental implant as an option for tooth replacement: The awareness of patients at a tertiary hospital in a developing country; Contemp Clin Dent. 2014 Jul-Sep; 5(3): 302-306.

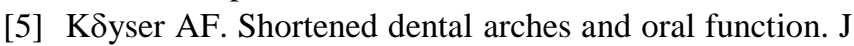
Oral Rehabil 1981; 8: 457-62

[6] Kumar RC, Pratap KV, Venkateswararao G. Dental implant as an option in replacing missing teeth: A patient awareness survey in Khammam, Andhra Pradesh. India J Dent Sci Indian J dent Sci. 2011;3:33-7

[7] Al-Johany S, Al Zoman HA, Al Juhaini M, Al Refeai M. Dental patients' awareness and knowledge in using dental implants as an option in replacing missing teeth: A survey in Riyadh, Saudi Arabia. Saudi Dent J. 2010; 22:183-8.

\section{Volume 6 Issue 7, July 2017}




\section{International Journal of Science and Research (IJSR) \\ ISSN (Online): 2319-7064}

Index Copernicus Value (2015): 78.96 | Impact Factor (2015): 6.391

[8] Tepper G, Haas R, Mailath G, Teller C, Zechner W, Watzak G, et al. Representative marketing-oriented study on implants in the Austrian population. I. Level of information, sources of information and need for patient information. Clin Oral Implants Res. 2003;14:621-33.

[9] Best HA. Awareness and needs of dental implants by patients in New South Wales. Aust Prosthodont J.1993;7:9-12

[10] Zimmer CM, Zimmer WM, Williams J, Liesener J. Public awareness and acceptance of dental implants. Int J Oral Maxillofac Implants. 1992;7:228-32.

[11]Berge TI. Public awareness, information sources and evaluation of oral implant treatment in Norway.Clin Oral Implants Res. 2000;11:401-8.

[12] Ellias AC, Sheiham A. The relationship between satisfaction with mouth and number, position and condition of teeth: Studies in Brazilian adults. J Oral rehab 1999; 26: 53-71.

[13] Steele JG, Treasure E, Pitts NB, Morris J, Bradnock G. Total tooth loss in the United Kingdom in 1998 and implications for the future. Br Dent J 2000; 189: 598603.

[14] Osterberg T, Hedegard B, Sater G. Variation in dental health in 70-year-old men and women in Goteborg, Sweden: a cross-sectional epidemiological study including longitudinal and cohort effects. Swed Dent J 1984; 8: 29-48. 